\title{
The Impact of Small Group Instruction on Preschool Literacy Skills
}

\author{
Majedah Abu Al Rub* \\ Yarmouk University, Jordan \\ Received: $22 / 1 / 2017$ \\ Accepted: 7/6/2017
}

\begin{abstract}
This study focused on 17 preschool students in a northern Jordan city. Preschoolers were taught specific literacy skills in a small group instructional setting. The students' skill level was assessed at the beginning and middle of the school year. The researcher's goal was to determine if teaching literacy skills in a small group setting would improve the skill level of the preschool students. Results showed that using small groups was an effective way to increase preschool students' literacy skill levels.
\end{abstract}

Keywords: Small group instruction, preschool literacy skills, Curriculum, preschool students.

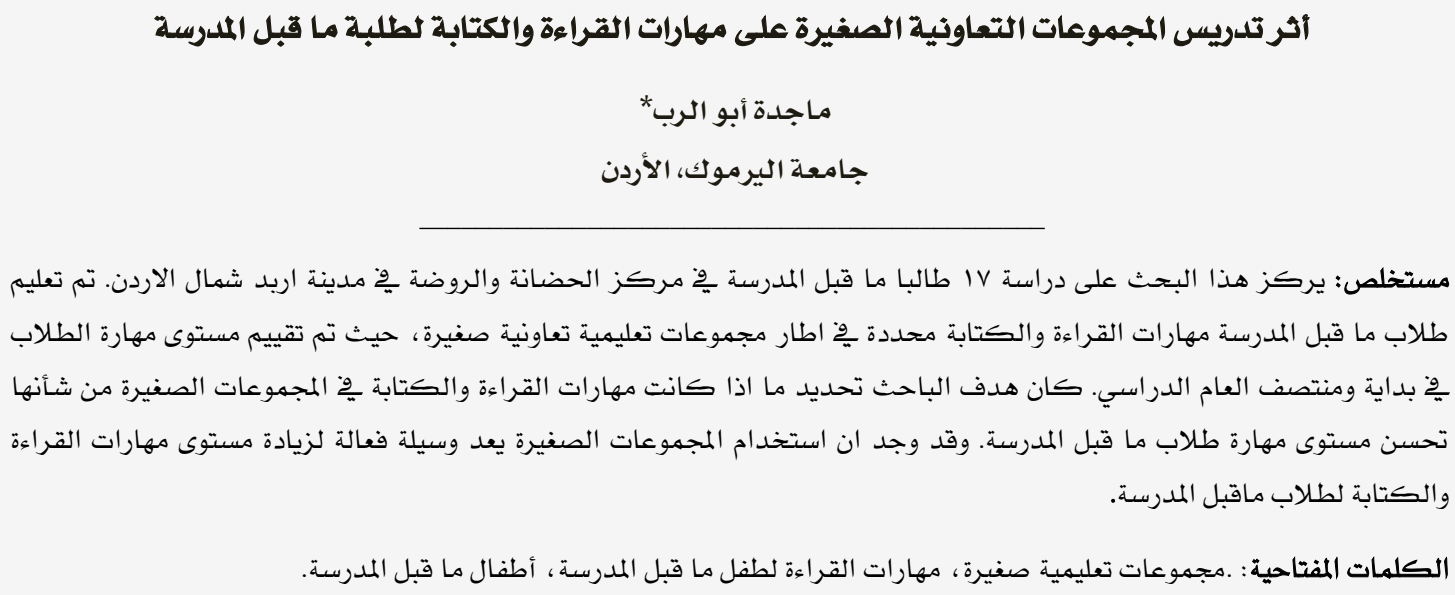

*majedah@yu.edu.jo 
Early childhood educators seek to introduce and build their students' literacy skills. Some preschool-aged children have already been exposed to a variety of literacy skills. For example, they may come from homes where parents read to them daily, point out letter and sound connections, and have already begun to learn to write their own names. However, many children do not come from these printrich backgrounds and school is their first experience with books, letters and writing. A preschool teacher's job is to help all the children make gains in their literacy knowledge, despite their diverse starting points.

A young child needs many different literacy skills to begin building a foundation for literacy success. Three of these specific skills are letter-sound recognition, letter formation, and book skills. According to an online report issued by the National Reading Panel (2000 as sited in Kamps et al. 2008), effective reading instruction includes teaching children to break apart and manipulate the sounds in words (phonemic awareness), teaching that these sounds are represented by letters of the alphabet which can then be blended together to form words (phonics), having them practice what they have learned by reading aloud with guidance and feedback (guided oral reading), and applying reading comprehension strategies to guide and improve reading comprehension. These skills can be taught in small classrooms or in large group settings.

This study's purpose was to examine the impact of teaching these skills in small group settings. This study assumed that small groups can be highly beneficial to children. Small groups give the teacher a closer look at what each child may be struggling with and the skills the children have already begun to develop. This study focused on the three literacy skills mentioned in the previous paragraph to narrow the large scope of research in this area.

The researcher first performed a baseline (Sept) assessment with students to determine their skill levels in these three literacy skills. This data guided instruction planning for the small group. Then, the teacher worked with students in small groups for several weeks and then performed a second (March) assessment. The importance of this study stems from providing insight into the impact of small group instruction on preschool literacy skills.
Data showing the benefits of small group instruction is useful to designing preschool literacy programs in Jordan. This research aimed to answer the following questions:

1. How does small group instruction impact preschool literacy skills?

2. How does small group instruction look like in a preschool classroom?

3. Is there a statistically significant difference on group scores when comparing between baseline and March assessments for each of the three skills after intervention (small group)?

\section{Literature Review}

Early childhood educators use many strategies to teach literacy skills to their students. Skills are introduced in large group meetings and reinforced during play in centers. The idea of teaching skills such as hand writing, letter recognition, and book skills in small group settings has recently been added to the preschool curriculum. Research shows that the more exposure to literacy a child has at a young age, the more successful the student will be in later years. Small groups can be an essential part of teaching young children literacy skills. The remainder of this section reviews relevant existing literature on literacy skills and small group instruction.

\section{Literacy Skills}

Preschool literacy skills include being able to name letters, form letters and make lettersound connections. According to Teaching Strategies, Inc. (2010a, 2010b), literacy development in the early years is critical for later success. The level to which a child progresses in reading and writing is one of the best predictors of whether the child will function competently in school and in life.

Piasta and Wagner (2010) found that a primary objective of preschool instruction and intervention is facilitating the development of alphabet knowledge, which is a hallmark of early literacy (p. 8). Whitehurst and Lonigan (1998) defined alphabet knowledge as children's familiarity with letter forms, names, and corresponding sounds, as measured by recognition, production, and writing tasks. Heroman and Jones (2004) said that knowledge of letters and how they work is an important component of literacy, and it in- 
volves much more than reciting the $\mathrm{ABC}$ song or recognizing individual letters. Readers must understand that a letter is a symbol that represents one or more sound. The authors added, "The idea that written spellings correspond to spoken words is called the alphabetic principle. Children's understanding of the alphabetic principle is a predictor of future reading success" (p. 28). Adams, (1990) and Steven and Newman (1986, p.30 as sited in Heroman and Jones 2004), stating that a prereader's alphabet knowledge is one of the single best predictors of eventual reading achievement.

The National Reading Panel $(2004,2008)$ stated that phonological sensitivity is also a strong predictor of later reading, writing, and spelling ability. Kamps et al. (2008) found that phonemic awareness skills should be emphasized to strengthen the oral/written language connection (p. 105). After examining 100,000 students on how students learn to read, the National Reading Panel (2000) issued an online report. The panel concluded the following definition of early reading instruction and intervention:

"Effective reading instruction includes teaching children to break apart and manipulate the sounds in words (phonemic awareness), teaching them that these sounds are represented by letters of the alphabet which can then be blended together to form words (phonics), having them practice what they have learned by reading aloud with guidance and feedback (guided oral reading), and applying reading comprehensions strategies to guide and improve reading comprehension." (p. 107)

Heroman and Jones (2004), quoting Adams (1990), added, "Familiarity of the letters of the alphabet and awareness of the speech sounds, or phonemes, to which they correspond, are strong predictors of the ease or difficulty with which a child learns to read" (p. 25). Further, they said that phonological awareness, also referred to as phonological sensitivity, is the act of hearing and understanding different sounds and patterns of spoken language. This research shows that alphabet knowledge and phonemic awareness are important indicators for a child to be a successful student. These studies show that skills should be introduced to preschool age children using specific strategies to help the children retain the information they are learning.

\section{Small Groups}

Small group instruction is becoming a more widely used way of teaching specific skills to preschool children. According to Katz (1999), the data on children's learning suggests that preschool and kindergarten experiences require an intellectually oriented approach in which children interact in small groups as they work together on projects that help them make increasing sense of their own experience. Katz added that the younger the children are, the greater the variety of teaching methods there should be, because the younger the children, the less likely they are to have been socialized into a standard way of responding to their social environment (p. 5).

Preschool teachers use a wide variety of teaching methods to engage their students on a daily basis. For example, large group instruction could be used to review everyday skills such as counting and letter identification. Large groups are also used to introduce a skill, for example letter formation, and then small group time is used to practice the skill, for example actually writing the letter.

Dodge, Colker, and Heroman (2002) said, "The purpose of small group time is to present activities briefly to a few children" (p. 86). Following this idea with the above example, small group time could be short and the children would practice writing the letter a few times. The teacher would watch the children form the letters and make any notes on their progress. Dodge Colker, and Heroman state: "the size of the group depends on the age and the individual needs of the children. Threeyear-olds will benefit more from informal small-group settings of two to four children. A small group for older preschoolers can be three to six children" (p. 86). When speaking of small groups Katz says that they should include constructions and dramatic play as well as a variety of early literacy and numeracy activities that emerge from the work of the investigation and the tasks of summarizing findings and sharing the experiences of the work accomplished. Kamps et al. (2008) also say that small bits of information are introduced in each lesson. Concepts are repeatedly reviewed in different contexts and modalities to strengthen the brain's pathways in depositing and recalling information, which enhances mastery. 
Prior research also indicated that smaller group sizes are an important contributing factor to the success of reading interventions (Kamps et al., 2008). Kamps et al. (2008) found that teachers and school staff were able to successfully provide small group interventions for the students. This finding suggests that the time to successfully implement the use of small group instruction into the daily schedule is possible. Kamps et al. (2008) also suggested that small groups should take less than ten minutes and do not always have to be the same lesson for each group. Children do not work without direct teacher intervention in small group work (Hastings and ChantreyWood, 2002). Gillies' studies (2003a, 2003b) showed that structured group work by teachers has more collaboration among students and they use higher thinking skills than groups with unstructured work. This study emphasized that the structure of tasks is more important than working well together.

\section{Method}

The participants in this study attended a preschool center in a northern Jordan city of Irbed. The study sample consisted of 17 preschool students who were 4 or 5 years old. These students attended preschool for 6 hours each day. Each day, the children participated in large group activities, snack time, small group activities, and free choice time. The daily small group activities were the focus of this research study. The activities in this study were normal classroom activities that the children were all used to participating.

The primary instrument that was used in this study was the Creative Curriculum Developmental Continuum for Ages 3-5. According to Colker et al. (2002), "The Developmental Continuum lays out the progression of development in each developmental area. It is made up of goals and objectives" (p. 42). Specifically, this study used the Language Development area of the Developmental Continuum. The goals and objectives in this area were further separated into two sections. The two sections were listening and speaking, and reading and writing. Skills from both areas were assessed during this research project. Each objective on the Developmental Continuum has three forerunners and three steps. Colker et al. (2002) said, "Because children develop at very different rates, these boxes do not represent a specific age; rather they show the sequence of achieving each objective" (p. 43). According to their continuum, step one (S1) represents the beginning level, the second step (S2) indicates the next level in reaching the objective and the third step (S3) represents the highest level of skill development. Forerunner skills are used for children who are not developing at the typical preschool pace.

For this study, students were assessed two times. The baseline (September) assessment occurred at the beginning of the school year to determine the developmental levels of the children in the class. This assessment occurred individually with the researcher and consisted of asking them ("Let's look at these letters. Can you tell me any of them?"). Based on their answers, each student was placed on one of the levels from the criteria (either forerunner or one of the three steps). The data from this assessment determined the needs of students individually and as a whole group. During mid-year, a second (March) assessment took place. The children again were placed on the Developmental Continuum according to the skills the researcher observed in the classroom. In all, the data that determined where the children were placed on the Developmental Continuum was a combination of classroom observation and small group activities.

Two other instruments were used to gather data in this study. One was the small group focus sheet and the other was anecdotal notes. The small group focus sheet was used during each small group activity. On the sheet, the researcher listed what she was looking for during the small group and made comments on the children's performance as well as what may need to be worked on further. Also, she used this documentation when determining what lessons to teach, as well as when determining if specific students need more one-onone work to help improve skills. Anecdotal notes were gathered during large group and free choice activities. The researcher utilized different methods of collecting data through observation and informal ways of recording observations such as jotting down a quick observation on post-it notes.

\section{Research Questions}

- How does small group instruction impact preschool literacy skills? 
- How does small group instruction look like in a preschool classroom?

- Is there a statistically significant difference on group scores when comparing between baseline and March assessments for each of the three skills after intervention (small group)?

\section{Definition of Terms}

Small Group Instruction: teaching a concept or skill with a selected group of children.

Creative Curriculum: a research-based developmentally-appropriate practice for teachers of preschool age children.

Baseline (Sept) Assessment: the first assessment of the school year, the purpose is to determine what skills the children enter school knowing.

March Assessment: the second assessment in the middle of the school year, the purpose is to determine what skills the children improved and achieved.

Anecdotal Notes: Quick notes which can be kept to monitor a child's progress or growth over time.

\section{Results}

The first research question dealt with determining the extent to which small group instruction impacted preschool literacy skills. To measure this, the researcher used the students' scores from the baseline data and assessments conducted after the study's intervention. Three objectives were assessed from the creative curriculum continuum. The researcher compared the scores of each of the objectives from baseline data to the postintervention assessment. The scores each child could receive, in order of progression, were: Forerunner 1, Forerunner 2, Forerunner 3, Step 1, Step 2, and Step 3. The assessment was a continuum meant to show growth over time. Figures 1, 2 and 3 show the class's performance during both the baseline and postintervention assessments. The three objectives are as follows:

Objective 45: demonstrates understanding of print concepts. This Objective focuses on skills such as knowing that print carries a message (Step 1) and knows each spoken word can be written down and read (Step 3). Objective 46: demonstrates knowledge of the alphabet. This Objective focuses on skills such as recognizing and identifying a few letters by name (Step 1) and Beginning to make letter- sound connections (Step 3). Objective 48: comprehends and interprets meaning from books and other texts. This Objective focuses on skills such as imitating the act of reading in play (Step 1) and retelling a story including many details and draws connections between story events (Step 3).

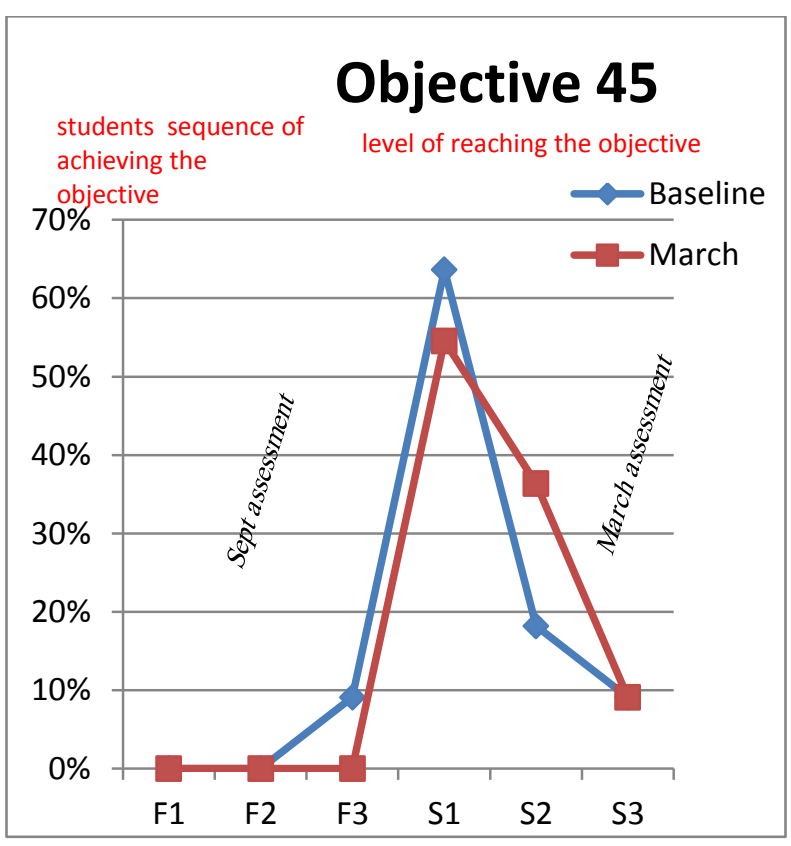

Figure 1: Assessment results for objective 45: "Students' ability to demonstrate understanding of print concepts."

Figure1 shows that $9 \%$ of students were at forerunner 3 (F3) on the baseline assessment which they recognize logos and pictures e.g., identify McDonald's logo; see picture label of beads on shelf and say beads go here and none of the students were at forerunner levels after the intervention. $64 \%$ of students were at Step 1 (S1) on the baseline assessment and 55\% of the students were at S1 after the intervention which they know that print carries the message e.g., point to printed label on shelf and say, "Cars go here"; looking at the name the teacher has written on another child's drawing, says, "Whose is this?" $18 \%$ of the students were at S2 on the baseline assessment and 36\% were at the same step on the March assessment they show general knowledge of how print works e.g., run finger over text left to right, top to bottom as he pretends to read; know that names begin with a big letter. This result shows marked growth from the intervention. The baseline assessment showed 9\% of the children were at Step 3, which indicates that the child has met the objective's goal and ready to move forward. The second assess- 
ment showed the same 9\% were at Step 3, which indicated that children know each spoken word can be written down and read e.g., touch a written word for every spoken word in a story; looking at a menu asks, "Which word says pancakes?" no additional students had moved forward to Step 3 after the intervention.

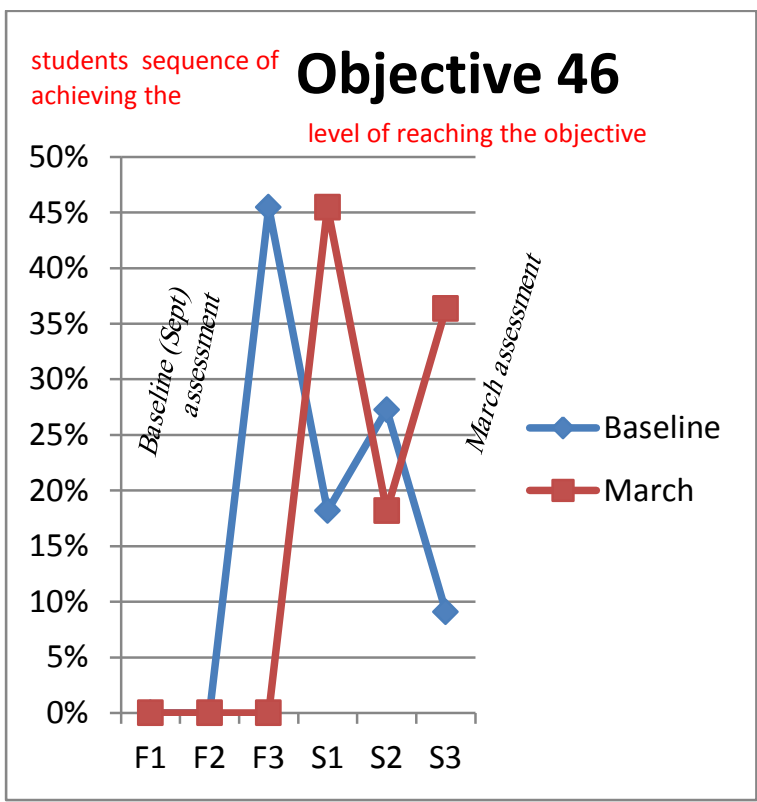

Figure 2: Assessment results for objective 46 "students ability to demonstrate knowledge of the alphabet"

Figure 2 shows that $45 \%$ of the students were at Forerunner 3 on the baseline assessment which indicates that they match two letters that are alike e.g., child matches letter $\mathrm{M}$ to another letter $\mathrm{M}$ and none of them were at F3 on the second assessment, this shows improvement. Eighteen percent of students were at Step 1 on the Baseline Assessment, while $45 \%$ of students were at Step 1 on the second assessment which indicates that they recognize and identify a few letters by name e.g., point to a cereal box and say, "That's $C$ like in my name".

Twenty-seven percent of students were at Step 2 on the Baseline, while $17 \%$ were at Step 2 on the second assessment which indicates that they recognize and name many letters e.g., use alphabet stamps and name the letters - " $\mathrm{D}, \mathrm{T}$, $\mathrm{M}$. Nine percent of students were at Step 3 on the baseline assessment and $36 \%$ of students were at this level on the second assessment which indicates that they could on S3 begin to make letter-sound connections e.g., write a big $\mathrm{M}$ and say, "This is for Mommy. These results show considerable improvement after the intervention.

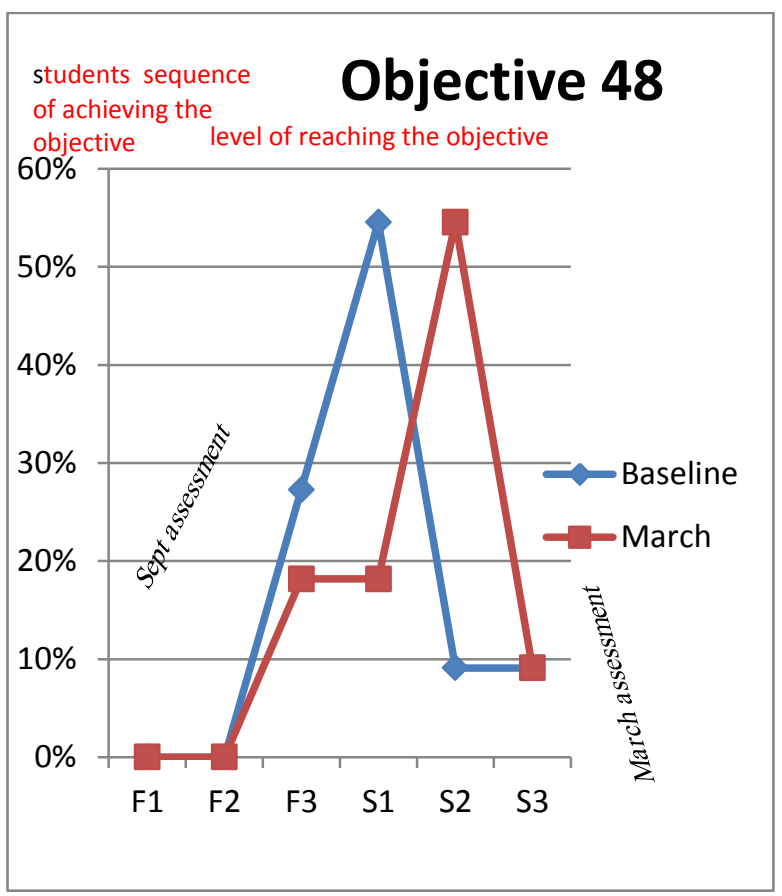

Figure 3: Assessment results for objective 48 "students' ability to comprehend and interprets meaning from books and other texts"

Figure 3 shows that $28 \%$ of the students were at Forerunner 3 in the baseline assessment, while $19 \%$ were at the same level in the second assessment which indicates that they relate story to self and share information e.g., after hearing a story about new shoes, says, " new shoes," and points to own shoes. At the baseline assessment, $55 \%$ of the students were at Step 1, while $18 \%$ were at the same level in the second assessment which they initiate act of reading n play e.g., hold up book and pretend to read to a baby doll; take out phonebook in dramatic play area to make a phone call. Step 2 showed the most difference between the two assessments as 9\% were at Step 2 on the baseline assessment but that number jumped to $55 \%$ on the second assessment. This result indicates considerable improvement on comparing and predicting story events; acting out main events of a familiar story e.g., compares own feelings about baby brother to those of character; re-enacts Three Billy Goats Gruff. The same students were at Step 3 after both the baseline and second assessment, 9\% which indicates that they retell a story including many details and draw connections between story events. 
The second research question dealt with examining how small group instruction looks like in a preschool classroom. The researcher started the project with 5 children in the small groups but ended up working with only 4 children at a time. Small group was based on instructional objectives in the Creative Curriculum Developmental Continuum.

The class was divided into groups of 4 and each group had a task. While one group was working with the researcher, the other groups would be working on a specific skill such as problem solving or fine motor work. Each group session took between five and ten minutes then the groups would rotate. During the small groups sessions the researcher kept track of the student's performance on the Small Group Focus Sheet. This sheet had the goal, materials needed, children's names and 2 or 3 things to focus on within each lesson.

For group work to be productive and effective, children make sure that all members in the group understand the learning task, can share actively, and work hard for the success of their group. Students working in groups would develop some social skills such as how to request help and how to provide help to their peers. In order to achieve the goal, the researcher and the teachers taught them how to engage in meaningful conversations about the topic or task and how to face and resolve conflicts. In addition, the researcher emphasized to teachers how to set up, promote, and sustain such group work, how to encourage the group's accountability for being on task, and when and how to intervene when problems arise (Gillies \& Ashman, 2004).

Table1

Means, Standard Deviations and Correlations and t-Values of Pre and Post Tests for Objectives 45, 46, and $48(\mathrm{~N}=17)$

\begin{tabular}{|c|c|c|c|c|c|c|}
\hline \multicolumn{2}{|c|}{ Objective: } & Mean & SD & $\mathrm{r}$ & $t$ & $\mathrm{df}$ \\
\hline \multirow{2}{*}{45} & Base-line & 4.35 & .79 & \multirow{2}{*}{$.834^{* *}$} & & \\
\hline & March & 4.59 & .71 & & $-2.22^{*}$ & 16 \\
\hline \multirow{2}{*}{46} & Base-line & 4.00 & 1.12 & \multirow{2}{*}{$.964^{* *}$} & & \\
\hline & March & 4.88 & .93 & & $-10.95^{* *}$ & 16 \\
\hline \multirow{2}{*}{48} & Base-line & 4.00 & .94 & \multirow{2}{*}{$.854^{* *}$} & & \\
\hline & March & 4.59 & .94 & & $-4.78^{\star *}$ & 16 \\
\hline
\end{tabular}

The third question dealt with examining if there was a statistically significant difference on mean scores after intervention. Results showed that there was a statistically significant difference on group scores when comparing between baseline and March assessments for each of the three skills after intervention (small group) (see table 1).

\section{Discussion}

This study focused on the effect of small group instruction on preschool literacy skills and whether using small group instruction would improve the literacy skills of preschool students. Figure 1 showed results from the before and after assessments regarding objective 45, which focused on children's understanding of print concepts. The children were asked to show the researcher the front and back of the book and then they were asked where to start reading the book. During the baseline assessment, many children pointed to the picture on the page rather than the text, but during the second assessment more of them began to point to the text on the page. The researcher then told the children that she would read the words and they were to put their finger on the text and follow along. She also asked children questions about the book and helped them use the pictures on the page to answer questions. The results showed that many of the children improved their understanding of print concepts from the first to the second assessment. The number of students in Step Two or Three rose from $27 \%$ to $45 \%$ after the intervention.

Figure 2 showed the results from the two assessments in regarding objective 46, which focused on the children knowledge of the alphabet. The researcher introduced letters of the alphabet during large group time and then in small groups, students were asked to identify the letter, write it and talk about its sound. The researcher also played games with the children where they had to sort pictures based on the first letter sound. For example, a picture of cat would go with the letter c. In the baseline assessment, $36 \%$ of students were at Step 2 and 3 on the Developmental Continuum, that number increased to $53 \%$ on the second assessment.

Figure 3 showed the results of objective 48, which focused on how the child comprehended and interpreted meaning from books and other texts. This is related to the child's to recall information from a story and even retell the story by acting it out or using props to show the sequence of events that took place during the story. In large group, the researcher read the story to the whole class and in small groups they used the felt board and pieces of felt that represent characters in the story to 
retell the story. The students also drew pictures of the events of a story. The children worked together to get the sequencing right or to assign who gets what part of the story. In the baseline assessment, $18 \%$ of students were at Step 2 or 3, while in the second assessment $64 \%$ of students were at these steps. This shows an improvement of $46 \%$ after the intervention.

According to the results of this study, a positive impact was found from using this small group instruction intervention to improve preschool literacy skills. This result coincides with Kamps et al. (2008) when they stated, "Concepts are repeatedly reviewed in different contexts and modalities to strengthen the brain's pathways in depositing and recalling information, which enhances mastery" (p. 105). This study's results also agrees with Katz (1999), who stated, "the data on children's learning suggest that preschool and kindergarten experiences require an intellectually oriented approach in which children interact in small groups as they work together on projects that help them make increasing sense of their own experiences" (p. 5). The findings from this study revealed that students in small groups in the classroom learned significantly in regards to language skills more than students who were not instructed in small groups. This is supported by Lou's et al. (1996) study which determined that small group instruction was most effective when groups consisted of 3 to 4 students, and the intervention was more effective.

This study reinforces the importance of preschool curriculum and demonstrates that using small groups can improve the literacy skills of preschool students. Although research studies on this topic were very limited when it came to preschool-aged students, many curricula books suggest teaching skills and concepts in small groups is a beneficial way to improve skills. Further research in this area based on preschool children would be beneficial to early childhood educators. Extending this concept by using small group instruction in other domains to improve math and social emotional skills is also suggested for further research.

\section{References}

Adams, M. J. (1990). Beginning to read: Thinking and learning about print. Cambridge, MA: MIT Press.

Dodge, D. T., Colker, L. J., \& Heromen, C. (2002). The creative curriculum for preschool ( $4^{\text {th }} E d$.). Washington D.C.: Teaching Strategies, Inc.

Elbaum, B., Vaughn, S., Hughes, M., Moody, S. W., \& Schumm, J. S. (2000). How reading outcomes of students with disabilities are related to instructional grouping formats: A meta-analytic review. In R. Gersten, E. P. Schiller, \& S. Vaughn (Eds.), Contemporary special education research: syntheses of knowledge base on critical instructional issues. Mahwah, N. J.: Erlbaum and Associates.

Gillies, R., (2003a).The behaviors, interactions, and perceptions of junior high school students during small-group learning. Journal of Educational Psychology, 95(1), 137-147.

Gillies, R., (2003b). Structuring cooperative group work in classrooms. International Journal of Educational Research, 39(2), 35-49.

Gillies, R., (2004). The effects of communication training on teachers' and students' verbal behaviors during cooperative learning. International Journal of Educational Research, 41(3), 257-279.

Hastings, N. \& Chantrey Wood, K. (2002). Reorganizing primary classroom learning. Buckingham, Open University Press.

Heroman, C., \& Jones, C. (2004). Literacy: The creative curriculum approach. Washington D.C.: Teaching Strategies, Inc.

Kamps, D., Abbott, M., Greenwood, C., Wills, H., Veerkamp, M., \& Kaufman, J. (2008). Effects of small-group reading instruction and curriculum differences for students most at risk in kindergarten. Journal of Learning Disabilities, 41(2),101-114.

Katz, L. G. (1999). Another look at what young children should be learning. ERIC Digest, 1-7.

Lou, Y. Abrami, P. C., Spence, J. C., Poulsen, C., Chambers, B., \& d" Apollonia, S. (1996). Within-class grouping: A meta-analysis. Review of Education Research, 66(4), 423-458 
National Reading Panel (1998). Teaching children to read: an evidence-based assessment of the scientific research literature on reading and its implications for reading instruction. Washington, DC: National Academy Press.

National Early Literacy Panel. (2004). A synthesis of research on language and literacy. Retrieved from: http://www. famlit.org /ProgramsandInitiatives/ Family Partnerships in Reading/index. cfm

National Literacy Panel. (2008). Developing early literacy: Report of the National Early Literacy Panel. Retrieved from http://www.nifl.gov/nifl/publication/p df/ NELPReport09.pdf.

Piasta, S. B., \& Wagner, R. K. (2010). Developing early literacy skills: A meta-analysis of alphabet learning and instruction. Reading Research Quarterly, 45(1)8-38.

Teaching Strategies, Inc. (2010a). Moving beyond the developmental continuum: Teaching strategies GOLD. Washington D.C.: Teaching Strategies, Inc.

Teaching Strategies, Inc. (2010b). Research foundation and teaching strategies GOLD assessment system. Washington D.C.: Teaching Strategies, Inc. 